\title{
ASSESSMENT OF THE IMPACT OF ROOF-LEVEL BUILDING FEATURES ON AIR POLLUTION INSIDE URBAN STREET CANYONS
}

\author{
BIDROHA BASU ${ }^{1,2}$, FRANCESO PILLA $^{2} \&$ AONGHUS MCNABOLA ${ }^{1,3}$ \\ ${ }^{1}$ Department of Civil, Structural and Environmental Engineering, Trinity College, Eire \\ ${ }^{2}$ School of Architecture, Planning and Environmental Policy, University College Dublin, Eire \\ ${ }^{3}$ Global Centre for Clean Air Research, University of Surrey, UK
}

\begin{abstract}
Air quality in urban street canyons is often known to be poor due to the restricted environment for dispersion created by the surrounding buildings. The present study investigates the installation of a deflector system at rooftop level in order to reduce air pollution inside a street canyon. Numerical simulations were conducted to model air pollution dispersion inside a two-dimensional street canyon. The distribution of $\mathrm{PM}_{2.5}$ air pollution concentration at different heights within the canyon were investigated, both with and without the presence of the deflector system, located at roof level. The simulations were repeated for different ambient wind velocities and for perpendicular wind directions. The results indicate that significant improvements in air quality inside the canyon can be achieved using the deflector system to increase the amount of air exchange taking place at roof level. The improvements in air quality were affected by the angle of inclination of the deflectors at roof level. The optimal combination of deflector dimensions, orientation and weather conditions resulted in a reduction of $\mathrm{PM}_{2.5}$ air pollution concentration of $61 \%$ inside the canyon. For practical implementation of the baffle plate, a real-time operating system based on the wind speed measurements needs to be developed, enabling variable inclination angles. Further research is also required to examine the impact of this concept in three dimensions and for varying canyon geometries. This proposed system of passive air pollution control offers significant scope to improve air quality in street canyons with a relatively inexpensive intervention at roof level.

Keywords: computational fluid dynamics, delayed detached eddy simulation, $P M_{2.5}$ air pollution, passive control structure, rooftop deflectors, street canyon.
\end{abstract}

\section{INTRODUCTION}

The construction of high-rise buildings adjacent to urban streets has reduced the exchange of air between roof level and street level, leading to a significant deterioration in air quality inside the street canyon, relative to open roadside environments [1]. With the considerable increase in human population in urban areas, improvements in air quality in the built environment has become an urgent matter. The complexity of the urban geometry and presence of multiple sources of pollutants increases the difficulty in controlling air pollution in an urban environment. One approach to addressing air quality is to control the pathway between the pollutant source and receptors. Over the past decade the use of passive control structures to increase pollutant dispersion by altering the dispersion pathway in street canyons in the urban environment has gained popularity [2], [3].

The goal of using passive control structures (PCS) is to engineer normal air flow patterns inside a street canyon such that these result in increased dispersion and reduced pollutant concentrations at target locations inside the canyon. Examples of PCS include solid barriers such as low boundary walls [4]-[6], road-side noise barriers, parked cars [7], [8] as well as porous barriers such as trees and vegetation [9]-[16], and hedgerows [17], [18]. McNabola et al. [6] found that use of PCS can reduce the air pollution concentration by up to $75 \%$ on footpaths. Gromke et al. [10] and Buccolieri et al. [11] noted that tree plantation can 
moderately reduce the air pollution near the windward walls in perpendicular wind conditions, while the pollution concentration increased at the leeward walls. They further noted that the changes in air pollution due to PCS is sensitive to the geometry (height to width ratio) of the street canyon. Heist et al. [19] found that the noise barriers can reduce the air pollution near ground level on the footpath while the pollution in the roadside increases. In general, PCS has the potential to reduce air pollution and do not require ongoing enforcement, significant capital investment, or changes in human behaviour.

However, the major drawback of using existing PCS are: (i) most of the PCS research to date have been designed to reduce pollution only at the footpaths in order to lessen exposure to pedestrians, (ii) in most street canyons use of PCS increases air pollution at other locations as a result of lowering these on the footpaths, particularly in the main roadways where majority of the population travels, and (iii) in several situations the PCS increase the air pollution concentration at the adjacent buildings where occupants reside [9]. Since the building occupants spend majority of their time in the buildings (residence or office) and a comparatively low amount of time on the footpaths, the use of conventional PCS might worsen exposure to air pollution in the population as a whole. Furthermore, the installation of conventional PCS (solid as well as porous) at street level inevitably restricts the movement of pedestrians and traffic by creating obstructions, and is as such impractical in many situations.

Previous investigations have assessed the impact of PCS using experimental or numerical methods of both. Experimental investigations have included measures of the differences in air quality upstream and downstream of a PCS in the field and in wind tunnel environments [9]-[11]. Numerous studies have used numerical techniques such as computational fluid dynamics packages (e.g. fluent, ANSYS, Openfoam, etc.) to predict the changes in air quality brought about by potential PCS installations. These have the advantage of lower cost and higher feasibility when assessing interventions like this in their early phases, compared to field-based or wind tunnel experiments [4]-[7]

This study investigates the use of rooftop baffle plates as an alternative PCS to overcome the drawbacks associated with previously researched PCS. The study aims to provide new information for the development of such a system to improve air quality for urban inhabitants in line with the sustainable development goals focusing on smart and sustainable cities [20]. Investigations were performed using computational fluid dynamics simulations to verify whether installation of rooftop baffle plates can reduce the overall air pollution inside the street canyon by introducing changes to the flow field inside the canyon, decreasing residence time and increasing dispersion. The analysis aims to identify the optimal configuration of the baffle plates in order to maximize the improvement of air quality.

\section{METHODOLOGY}

This study assesses changes in air pollution concentrations brought about inside a street canyon due to introduction of a baffle plate system acting as a PCS installed at rooftop level. The underlying concept being tested here was whether the introduction of a baffle plate system at roof level could be used to encourage a greater degree of mixing between the relatively unpolluted air at roof level, with the more polluted volume of air constrained within the street canyon. Greater mixing between the roof level and canyon air would result in a lower residence time for pollutants emitted at road level in the canyon, lowering concentrations within the canyon as a whole, as opposed to just on footpaths.

For this study, a hypothetical street canyon has been selected. The road width (W) in the study area is $20 \mathrm{~m}$ ( $15 \mathrm{~m}$ road and $2.5 \mathrm{~m}$ footpath on both sides). The buildings adjacent to the street have a height $(\mathrm{H})$ of $16 \mathrm{~m}$. The $\mathrm{HW}$ ratio of the street canyon was therefore 0.8 . 
The simulation study was performed under two different ambient wind velocities: $2 \mathrm{~m} / \mathrm{s}$ (low wind); and $4 \mathrm{~m} / \mathrm{s}$ (average wind). The air pollutant was considered to be solid carbon particles (representing $\mathrm{PM}_{2.5}$ ) that is emitted at the centre of the road at a height of $0.2 \mathrm{~m}$ from the ground, the approximate height of vehicle exhaust. The emission rate was $1 \mathrm{mg} / \mathrm{s}$.

Each of the simulations were run for $10 \mathrm{~min}$ at a time interval of $0.1 \mathrm{~s}$. The pollutant was injected after from 2 min until $5 \mathrm{~min}$ in the simulation time period. A delay in injecting the pollutant was adopted to ensure that the flow field inside the street canyon was not in a transient state. The injection of pollutants were stopped after 5 min to assess the residence time of the pollutant inside the canyon before and after introduction of the baffle plates. The average pollution concentration was monitored at four different heights inside the canyon $(0.5 \mathrm{~m}, 1 \mathrm{~m}, 2 \mathrm{~m}$ and $4 \mathrm{~m})$ for each simulation, and for the entire duration of each simulation. The difference in average pollution at those selected heights before and after introducing the baffle plates in the rooftops were estimated. In situations where the mean concentration averaged over the time period of the simulation was less than after the introduction of the baffle plates, it indicated that the plate had been able to reduce the air pollution at the chosen monitoring height within the street canyon.

The model domain extended by an amount of $\mathrm{H}$ above the building roof level and by $16 \mathrm{~m}$ on either side of the street canyon for the simulation (see Fig. 1). The location of the baffle plate was also shown in Fig. 1 . The plate was $1 \mathrm{~m}$ in length and offset by $1 \mathrm{~m}$ from the edge of the building. The total length of the baffle plate was considered to be $1 \mathrm{~m}$ and the angle of inclination was assumed to be $\theta$. The baffle plate was also offset by $1 \mathrm{~m}$ from the edge of the building. Various iterations of the length and offset dimensions of the baffle were performed and the dimensions presented here gave the optimal results. These iterations are not reported here for brevity.

Dimensions in meter

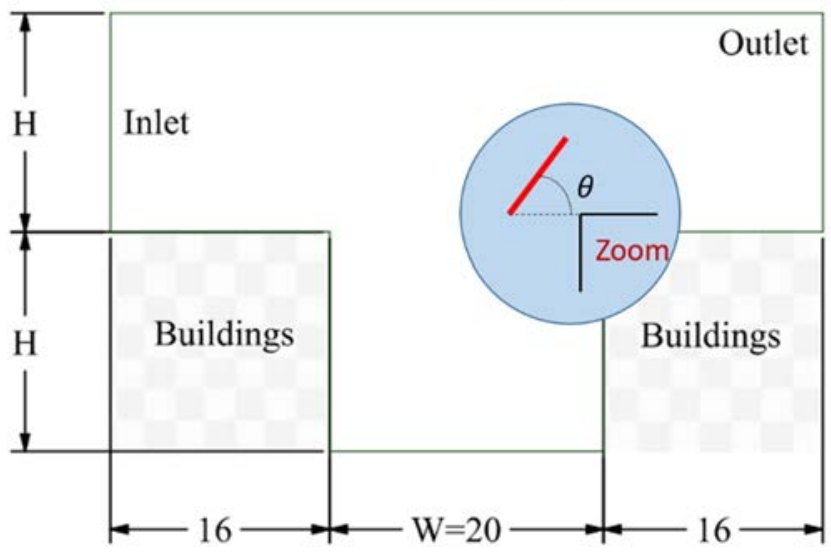

Figure 1: Modelled street canyon layout, where the baffle plate is shown in red.

In the simulation, the flow fields were considered to be in transient state and a densitybased solver has been used in ANSYS Fluent. Furthermore, the outlets were chosen to be pressure-based, while the buildings and road section were assumed to be made of concrete (roughness constant equals to 0.5), where no-slip flow condition were implemented. The maximum mesh size considered in the study were $0.2 \mathrm{~m}$ in size. Meshing in the road, building 
walls and building rooftops were considered to be hard mesh, while the interior region were considered to have a soft mesh with a bias of 2. To solve the flow field, delayed detached eddy simulation (DDES) in ANSYS has been adopted in this study, based on the SpalartAllmaras model.

\section{RESULTS}

Investigations were first performed to assess the accuracy of the DDES simulation study by comparing with benchmark results shown in Kovar-Panskus et al. [21]. The incoming velocity and $\mathrm{H} W \mathrm{~W}$ ratio were selected as per the benchmark case studies and the corresponding velocity profiles were noted after steady state was reached. Comparison of the velocity profile and flow fields obtained using the DDES model based simulation and that obtained from wind tunnel experiments by Kovar-Panskus et al. [21] indicate that the DDES results matched closely with the experimental results (see Fig. 2).

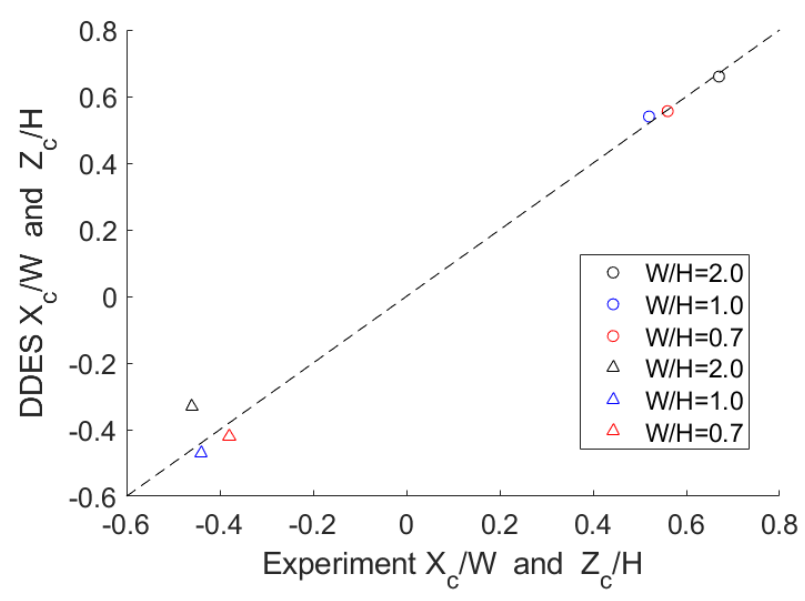

Figure 2: Comparison between the location of primary vortex centre $\left(\mathrm{X}_{\mathrm{c}}\right.$ and $\left.\mathrm{Z}_{\mathrm{c}}\right)$ obtained from experimental study (Kovar-Panskus et al. [21]) and DDES study. The circles indicate vortex centre $\mathrm{X}_{\mathrm{c}} / \mathrm{W}$ while the triangles indicate vortex centre $\mathrm{Z}_{\mathrm{c}} / \mathrm{H}$.

Simulations were first performed without the baffle plates and the average concentration of $\mathrm{PM}_{2.5}$ at the selected heights were monitored. As the optimal angle of inclination $\theta$ of the baffle plate was not known a priori, the angle $\theta$ varied from $0^{\circ}$ to $90^{\circ}$ at an interval of $15^{\circ}$. The difference in pollution concentration with and without the baffle plates were estimated for every time step ranging from $2 \mathrm{~min}$ to $10 \mathrm{~min}$ at an interval of $0.1 \mathrm{~s}$. It can be noted that since the pollutants were introduced in the street canyon at $\mathrm{t}=2 \mathrm{~min}$, the pollution concentration in the canyon until that time was zero. Differences in the mean pollution concentration at the chosen heights for each time step were plotted as boxplots shown in Fig. 3. Positive differences indicated that the mean pollution at the chosen height was reduced due to the introduction of the baffle plate at roof level. The difference in mean pollution concentration, in terms of percentage change at those chosen heights, averaged over the entire time period of the simulation corresponding to different wind velocities, were also estimated and are shown in Table 1. The percentage changes were calculated as the ratio between changes in average pollution concentration with and without the baffle plate system. 

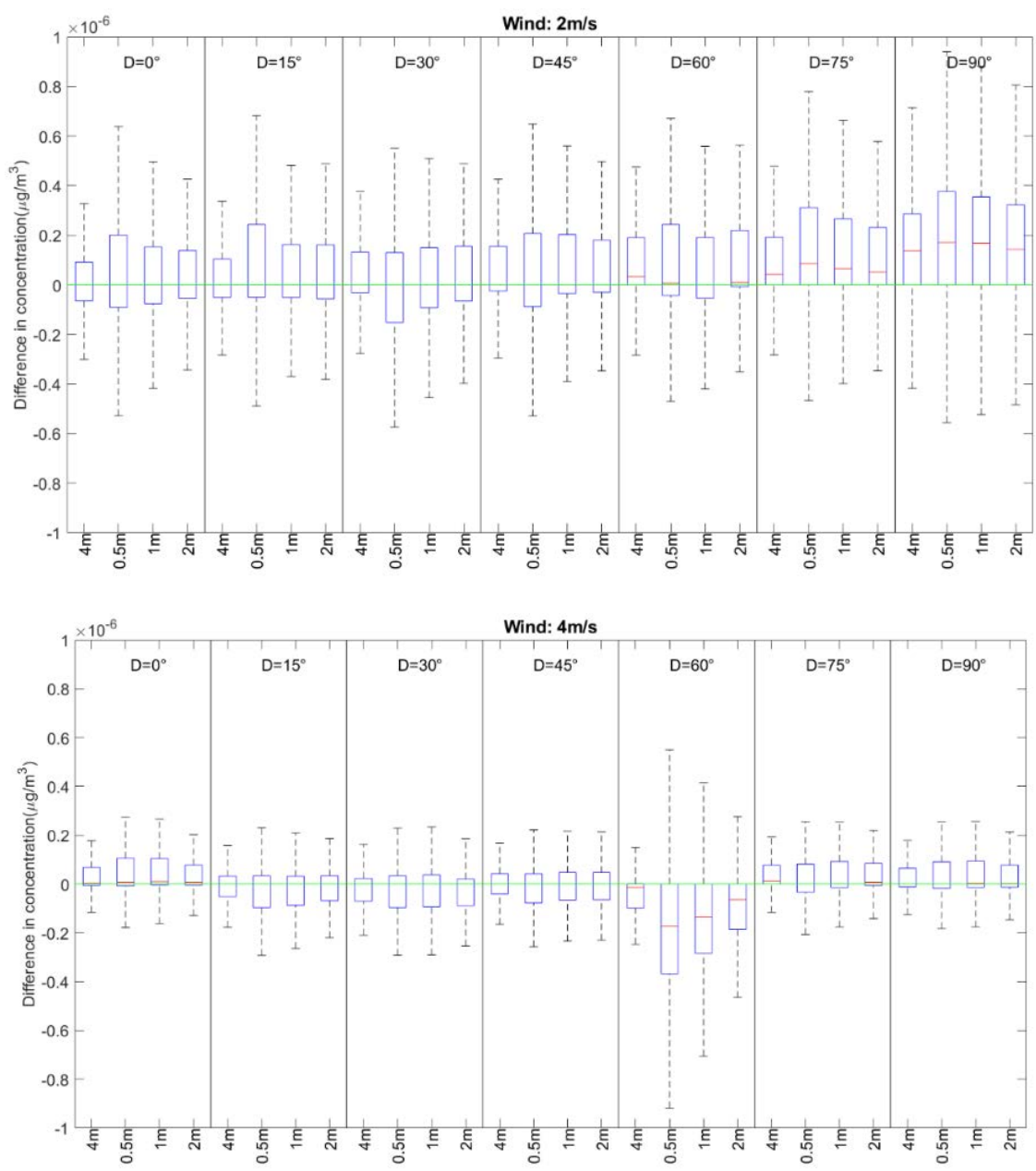

Figure 3: Difference in $\mathrm{PM}_{2.5}$ concentration at chosen heights for different wind velocities and $\mathrm{H} / \mathrm{W}$ ratios. Positive values indicate the pollution has reduced due to the baffle plate.

Fig. 3 and Table 1 indicate that significant reductions in average air pollution concentration can be achieved at various heights within the canyon, for varies ambient wind speeds. Maximum reductions of up to 55.5\% were found. Fig. 2 and Table 1 also indicate that the optimal angle of inclination varied with changes in the incoming wind velocity. For the $H W$ considered of 0.8 , the optimal angle was found to be $90^{\circ}$ for a low wind, while the optimal angle changes to $0^{\circ}$ for average wind velocities. In the case of low wind $(2 \mathrm{~m} / \mathrm{s})$, the presence of baffle plate was found to reduce air pollution within the canyon by up to $55.5 \%$ while maximum improvement for average wind $(4 \mathrm{~m} / \mathrm{s})$ was found to be $25.2 \%$. Greater improvements in canyon mixing and dispersion at lower winds speeds should also be noted as more impactful considering pollutant concentration will be higher in such conditions. It can also be noted that the impact of the baffle system varied depending on the height within the canyon at which air pollution concentrations were monitored $(0.5$ to $4 \mathrm{~m})$. 
Table 1: Percentage change in $\mathrm{PM}_{2.5}$ concentration with and without introduction of baffle plate at different inclination angles corresponding to different wind velocities and $\mathrm{H} / \mathrm{W}$ ratios. Positive values (shown in bold) indicate the pollution has reduced due to the baffle plate. Values shown in italics correspond to the selected overall optimum baffle angle.

\begin{tabular}{||c||c|c|c|c||c|c|c|c||}
\hline \multicolumn{1}{|c||}{$\theta$} & \multicolumn{4}{c||}{$2 \mathrm{~m} / \mathrm{s}$} & \multicolumn{4}{c||}{$4 \mathrm{~m} / \mathrm{s}$} \\
\cline { 2 - 9 } & $0.5 \mathrm{~m}$ & $1 \mathrm{~m}$ & $2 \mathrm{~m}$ & $4 \mathrm{~m}$ & $0.5 \mathrm{~m}$ & $1 \mathrm{~m}$ & $2 \mathrm{~m}$ & $4 \mathrm{~m}$ \\
\hline $0^{\circ}$ & $\mathbf{1 3 . 7}$ & $\mathbf{1 0 . 2}$ & $\mathbf{1 2 . 4}$ & $\mathbf{4 . 2}$ & $\mathbf{2 6 . 7}$ & 31.4 & $\mathbf{2 8 . 6}$ & $\mathbf{2 5 . 4}$ \\
\hline $15^{\circ}$ & $\mathbf{1 4 . 2}$ & $\mathbf{1 4 . 1}$ & $\mathbf{1 4 . 5}$ & $\mathbf{8 . 0}$ & -11.4 & -13.7 & -11.1 & -8.4 \\
\hline $30^{\circ}$ & -1.0 & $\mathbf{6 . 3}$ & $\mathbf{1 1 . 0}$ & $\mathbf{1 5 . 5}$ & -10.1 & -11.6 & -18.8 & -17.7 \\
\hline $45^{\circ}$ & $\mathbf{9 . 9}$ & $\mathbf{1 7 . 0}$ & $\mathbf{1 9 . 1}$ & $\mathbf{1 9 . 2}$ & -3.2 & $\mathbf{1 . 0}$ & $\mathbf{1 . 2}$ & $\mathbf{7 . 4}$ \\
\hline $60^{\circ}$ & $\mathbf{1 1 . 3}$ & $\mathbf{9 . 0}$ & $\mathbf{2 5 . 6}$ & $\mathbf{3 2 . 4}$ & -117.4 & -107.8 & -70.7 & -35.7 \\
\hline $75^{\circ}$ & $\mathbf{2 0 . 6}$ & $\mathbf{2 8 . 4}$ & $\mathbf{3 2 . 9}$ & $\mathbf{3 4 . 6}$ & $\mathbf{1 2 . 8}$ & $\mathbf{2 4 . 3}$ & $\mathbf{2 9 . 5}$ & $\mathbf{3 2 . 1}$ \\
\hline $90^{\circ}$ & $\mathbf{1 9 . 3}$ & $\mathbf{4 5 . 5}$ & $\mathbf{5 5 . 5}$ & $\mathbf{6 1 . 2}$ & $\mathbf{2 0 . 1}$ & $\mathbf{2 5 . 2}$ & $\mathbf{2 4 . 7}$ & $\mathbf{2 3 . 7}$ \\
\hline
\end{tabular}

Furthermore it can be noted from Table 1 that, even though a constant baffle angle would not provide improved air quality for all wind velocities considered it was possible to identify an angle with positive results for both scenarios considered. Therefore a variable angle deflector system which can respond to changes in ambient wind velocity and direction is crucial for the successful operation of such a system.

In general, it can be concluded that the simulation study indicates that the baffle plate reduces the air pollution inside the street canyon with the correct setup of baffle dimensions and orientation. To investigate the reason for improvement in air quality, the velocity profile with and without baffle plates and their differences are plotted in Fig. 3 for a $2 \mathrm{~m} / \mathrm{s}$ wind speed. Plots of $\mathrm{PM}_{2.5}$ concentration inside the street canyon after the 10 min simulation time period, with and without the baffle plate, are also shown in Fig. 4 for both wind speeds. It can be seen that fewer numbers of particles are present inside the canyon with the baffle after $10 \mathrm{~min}$. This is despite the fact that the same rate of emissions is applied to both canyons from $2 \mathrm{~min}$ to $5 \mathrm{~min}$ during the simulations and indicates that more of the particles have left the canyon with the baffle at $10 \mathrm{~min}$ due to the reduced residence time it causes.

\section{DISCUSSION}

The simulation results shown in Table 1 and Fig. 2 indicate that introduction of baffle plate at the rooftop can, in general, reduce the air pollution inside the street canyon considerably. Fig. 3 indicates that the introduction of the baffle plate increases the velocity of the air flow inside the canyon, which in turn creates higher turbulence leading to lower residence time, thus removing a considerable amount of particles from the canyon. Increases in turbulence can be considered to be the primary reason for the reduction of air pollution inside the canyon. It can be noted from Fig. 3 that the presence of the baffle plate, in general, increases the velocity of the flow along the building walls and the road of the canyon, which indicate that the turbulence had been increased inside the canyon due to introduction of the baffle plate. 


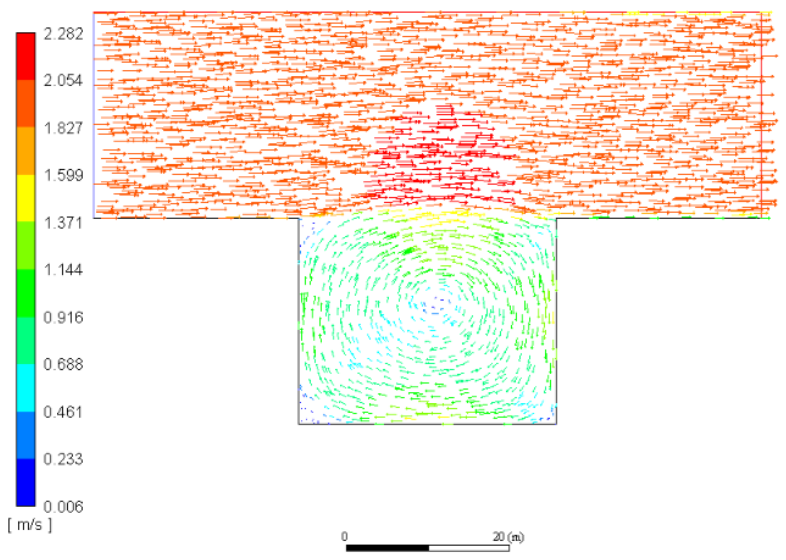

(a)
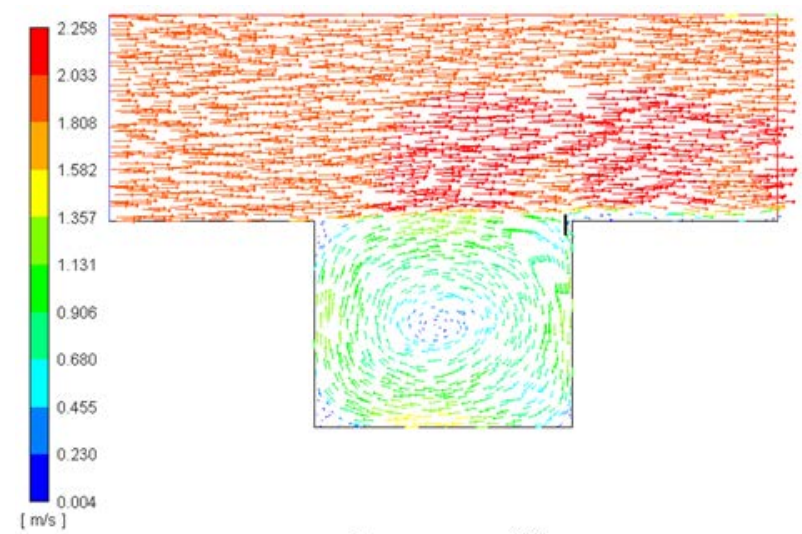

(b)



(c)

Figure 4: At $10 \mathrm{~min}$ time period of simulation for $2 \mathrm{~m} / \mathrm{s}$ wind speed. (a) Velocity profile without baffle plate; (b) Velocity profile with baffle plate; and (c) Differences in velocity between the previous two cases in $\mathrm{m} / \mathrm{s}$. 
In comparison to the level of air pollution concentration reductions achieve in similar modelling assessments of PCS located at ground level using solid or porous barriers the maximum reduction achieved here compares very favourably [9], [22]. This is particularly the case when considering that the reductions achieved here applied across the air quality in the full street canyon as opposed to solely in the wake of the barrier or on footpaths.

Comparison of the concentration profile obtained based on simulations with and without the baffle plates indicate that total number of particles present in the canyon has reduced significantly after the introduction of the plate (see Fig. 5). Fig. 5 also indicates that the maximum residence time of the particles present in the canyon also reduced by $0-30 \mathrm{~s}$. This indicates that the baffle plate not only reduces pollution inside the canyon, but also helps to remove the particles at a faster rate from the area. The primary reason for reduction in pollution due to the baffle plate is that it is designed to introduce more air flow from roof level into the canyon. In situations where the relatively cleaner roof-level air gets mixed with the more polluted canyon air, the pollution concentration reduces inside the canyon. Furthermore, with introduction of more air, turbulence increases inside the canyon, which in turn forces the pollutant to be removed from the canyon at faster rate, resulting in reduction of residence time of the pollutants inside the canyon.

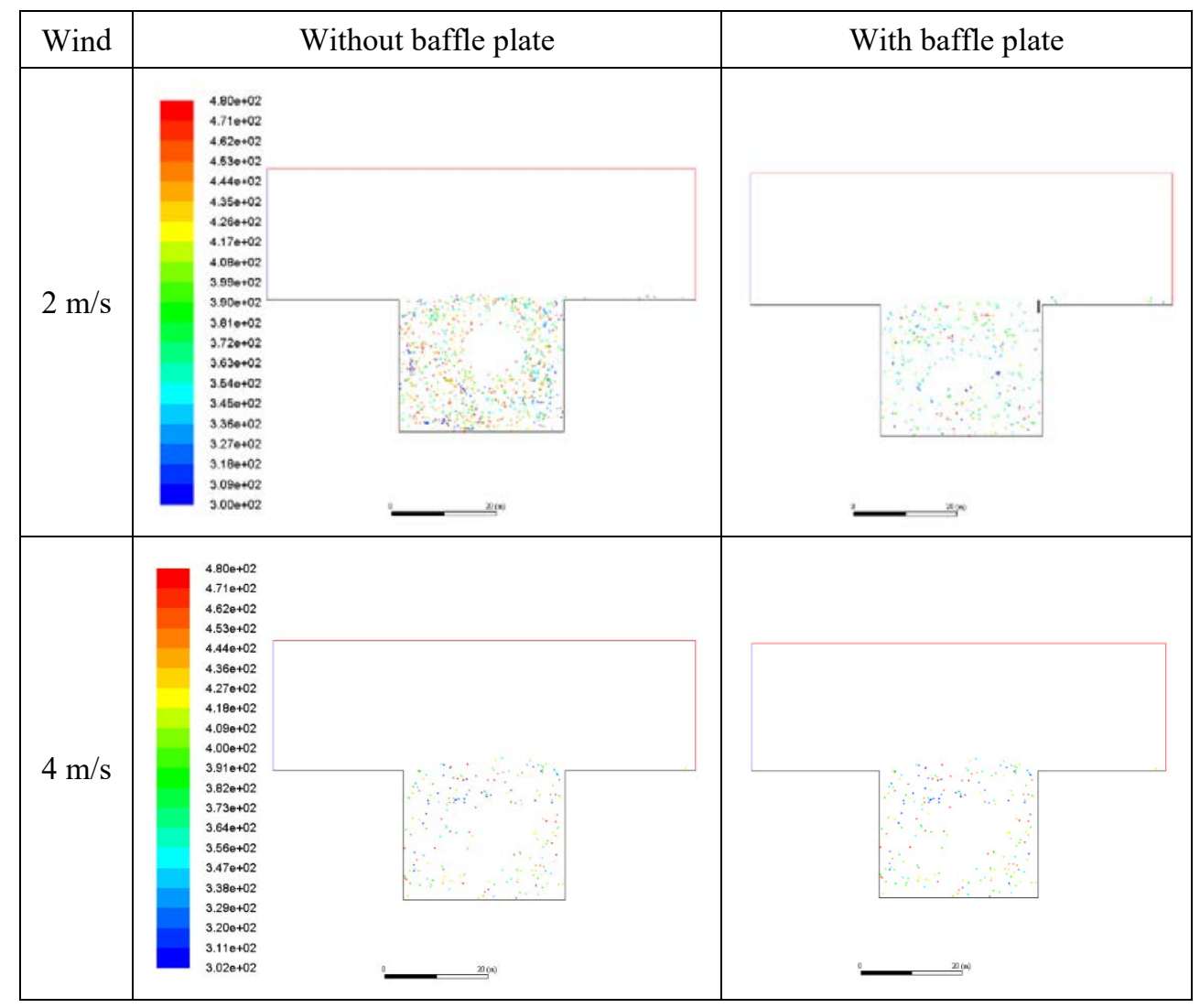

Figure 5: $\mathrm{PM}_{2.5}$ concentration profile after $10 \mathrm{~min}$ of simulation with and without baffle plates for $2 \mathrm{~m} / \mathrm{s}$ and $4 \mathrm{~m} / \mathrm{s}$ wind speed. 
One interesting point to be noted from Table 1 and Fig. 2 is that introduction of the baffle plate placed at a certain angle can substantially improve the air quality inside the street canyon. However, if the angle was changed for the same wind speed the baffle plate can contribute to a significant increase in air pollution concentrations. Furthermore, it has been noted that with changes in wind speed the angle of inclination of the baffle plate needs to be changed. For example, it can be noted that when baffle plate is orientated at $\theta=15^{\circ}$ it reduces the air pollution in the canyon for mild wind $(2 \mathrm{~m} / \mathrm{s})$, whereas for average wind speed $(4 \mathrm{~m} / \mathrm{s})$ the same orientation baffle plate increase the air pollution, and the position of the plate needs to be changed to horizontal to improve the air quality. This indicates that a real-time operating system based on the wind speed measurements needs to be incorporated here for the practical implementation of this concept. The primary reason for considerable changes in air quality corresponding to different baffle plate angles for different incoming velocities is that the circulation pattern of the turbulence inside the canyon is highly dependent on two factors: the ambient wind speed and the H/W ratio of the canyon. Though, in general, the baffle plate helps in the mixing of fresh roof-level air with the more polluted canyon air, however, in some specific angle of inclination the baffle plate can reduce the air flow inside the canyon due to obstructions. Furthermore, introduction of one baffle plate at a chosen angle cannot increase the turbulence at every location inside the canyon.

It should also be noted that findings in this research, while serving to highlight a potentially important new mechanism of canyon air pollution control, is subject to several limitations which will require further study. Simulations were conducted in two dimensions and therefore these have excluded a number of factors such as the effect of varying wind directions. The present results only indicate the performance of the baffle system in cross wind conditions. Further work is required to explore the concept further for all wind directions. The concept also requires further exploration to understand how it could perform when considering more complex canyon geometries, including differing roof-shapes, asymmetric canyons, and gaps in buildings. The promising results found here in two dimensions for flat roofs and symmetric canyons, demonstrate that further investigation of the aforementioned complexities is warranted. They indicate that this method has potential to improve air quality but significant work remains to prove this potential in a real environment.

\section{CONCLUSION}

The study presents the introduction of baffle plates at rooftop level to increase the turbulence inside a canyon resulting in reductions of air pollution concentrations. The advantage of using baffle plates in the rooftops instead of other passive control structures, such as low boundary walls, is that the plates do not obstruct the movement of vehicles and pedestrians in the roadway of the canyon. Also, most of the existing passive control structures focus on reducing the air pollution on the footpaths, which might increase the pollution inside the roadway affecting passengers inside vehicles. The baffle plate can be used to reduce the overall concentration inside the canyon. A delayed detached eddy simulation based study was performed to simulate the velocity and air pollution inside a 2-dimensional street canyon. Different incoming wind velocities were considered for the simulation studies. The analysis indicates that the introduction of baffle plates corresponding to different angles of inclination can improve the air quality inside the canyon by significant amount (up to 55.5\%). This observation indicates that a real-time operating system based on the wind speed measurements needs to be incorporated for the practical implementation of this concept in real world scenario. Future work is required to assess if these potential positive impacts can translate into real-world operation. 


\section{ACKNOWLEDGEMENTS}

The authors would like to acknowledge the European Community's H2020 Programme for part funding this research through Project Grant Agreement No. 689954. The authors would also like to acknowledge the Irish Environmental Protection Agency's Research Programme 2014-2020 for part funding this research through Project Grant Number 2019-PhD-AF-6. The EPA Research Programme is a Government of Ireland initiative funded by the Department of Communications, Climate Action and Environment.

\section{REFERENCES}

[1] Gallagher, J., Gill, L.W. \& McNabola, A., The passive control of air pollution exposure in Dublin, Ireland: A combined measurement and modelling case study. Science of the Total Environment, 458, pp. 331-343, 2013.

[2] King, E.A., Murphy, E. \& McNabola, A., Reducing pedestrian exposure to environmental pollutants: A combined noise exposure and air quality analysis approach. Transportation Research Part D: Transport and Environment, 14(5), pp. 309-316, 2009.

[3] McNabola, A., New directions: Passive control of personal air pollution exposure from traffic emissions in urban street canyons. Atmospheric Environment, 24(44), pp. 29402941, 2010.

[4] Gallagher, J., Gill, L.W. \& McNabola, A., Numerical modelling of the passive control of air pollution in asymmetrical urban street canyons using refined mesh discretization schemes. Building and Environment, 56, pp. 232-240, 2012.

[5] McNabola, A., Broderick, B.M. \& Gill, L.W., Reduced exposure to air pollution on the boardwalk in Dublin, Ireland. Measurement and prediction. Environment International, 34(1), pp. 86-93, 2008.

[6] McNabola, A., Broderick, B.M. \& Gill, L.W., A numerical investigation of the impact of low boundary walls on pedestrian exposure to air pollutants in urban street canyons. Science of the Total Environment, 407(2), pp. 760-769, 2009.

[7] Gallagher, J., Gill, L.W. \& McNabola, A., Optimizing the use of on-street car parking system as a passive control of air pollution exposure in street canyons by large eddy simulation. Atmospheric Environment, 45(9), pp. 1684-1694, 2011.

[8] Abhijith, K.V. \& Gokhale, S., Passive control potentials of trees and on-street parked cars in reduction of air pollution exposure in urban street canyons. Environmental Pollution, 204, pp. 99-108, 2015.

[9] Gallagher, J., Baldauf, R., Fuller, C.H., Kumar, P., Gill, L.W. \& McNabola, A., Passive methods for improving air quality in the built environment: a review of porous and solid barriers. Atmospheric Environment, 120, pp. 61-70, 2015.

[10] Gromke, C., Buccolieri, R., Di Sabatino, S. \& Ruck, B., Dispersion study in a street canyon with tree planting by means of wind tunnel and numerical investigations: Evaluation of CFD data with experimental data. Atmospheric Environment, 42(37), pp. 8640-8650, 2008.

[11] Buccolieri, R., Gromke, C., Di Sabatino, S. \& Ruck, B., Aerodynamic effects of trees on pollutant concentration in street canyons. Science of the Total Environment, 407(19), pp. 5247-5256, 2009.

[12] Amorim, J.H., Rodrigues, V., Tavares, R., Valente, J. \& Borrego, C., CFD modelling of the aerodynamic effect of trees on urban air pollution dispersion. Science of the Total Environment, 461, pp. 541-551, 2013. 
[13] Ottelé, M., van Bohemen, H.D. \& Fraaij, A.L., Quantifying the deposition of particulate matter on climber vegetation on living walls. Ecological Engineering, 36(2), pp. 154-162, 2010.

[14] Pugh, T.A., MacKenzie, A.R., Whyatt, J.D. \& Hewitt, C.N., Effectiveness of green infrastructure for improvement of air quality in urban street canyons. Environmental Science and Technology, 46(14), pp. 7692-7699, 2012.

[15] Salim, S.M., Cheah, S.C. \& Chan, A., Numerical simulation of dispersion in urban street canyons with avenue-like tree plantings: comparison between RANS and LES. Building and Environment, 46(9), pp. 1735-1746, 2011.

[16] Gromke, C., A vegetation modeling concept for building and environmental aerodynamics wind tunnel tests and its application in pollutant dispersion studies. Environmental Pollution, 159(8-9), pp. 2094-2099, 2011.

[17] Gromke, C., Jamarkattel, N. \& Ruck, B., Influence of roadside hedgerows on air quality in urban street canyons. Atmospheric Environment, 139, pp. 75-86, 2016.

[18] Li, X.B., Lu, Q.C., Lu, S.J., He, H.D., Peng, Z.R., Gao, Y. \& Wang, Z.Y., The impacts of roadside vegetation barriers on the dispersion of gaseous traffic pollution in urban street canyons. Urban Forestry and Urban Greening, 17, pp. 80-91, 2016.

[19] Heist, D.K., Perry, S.G. \& Brixey, L.A., A wind tunnel study of the effect of roadway configurations on the dispersion of traffic-related pollution. Atmospheric Environment, 43(32), pp. 5101-5111, 2009.

[20] United Nations, Transforming Our World: The 2030 Agenda for Sustainable Development. https://sustainabledevelopment.un.org/post2015/transformingourworld. Accessed on 31 Dec. 2019.

[21] Kovar-Panskus, A., Louka, P., Sini, J.F., Savory, E., Czech, M., Abdelqari, A., Mestayer, P.G. \& Toy, N., Influence of geometry on the mean flow within urban street canyons: A comparison of wind tunnel experiments and numerical simulations. Water, Air and Soil Pollution: Focus, 2(5-6), pp. 365-380, 2002.

[22] Abhijith, K.V., Kumar, P., Gallagher, J., McNabola, A., Baldauf, R., Pilla, F., Broderick, B., Di Sabatino, S. \& Pulvirenti, B., Air pollution abatement performances of green infrastructure in open road and built-up street canyon environments: A review. Atmospheric Environment, 162, pp. 71-86, 2017. 